\title{
Perfis e limites na pró-atividade dos novos sujeitos midiáticos advindos com a Internet
}

Profiles and limits of new mediatic subjects' proactivity made possible by the Internet

Carlos Alberto ZanottI

Professor e pesquisador da Faculdade de Jornalismo da PUC-Campinas

E-mail:zanotti@sti.com.br

\section{Resumo}

Este trabalho apresenta resultados de pesquisa realizada a partir de 440 comentários, enviados via Internet, às colunas de leitores de três publicações jornalísticas da cidade de Campinas (SP): um jornal diário, uma revista semanal e um portal noticioso, todos pertencentes a um mesmo grupo editorial. Enquanto cenários discursivos, estes espaços refletem perfis, preocupações e interesses dos novos sujeitos midiáticos advindos com a mais importante ferramenta da nova mídia - o correio eletrônico. Além de registrar uma ainda clara preferência pela utilização do meio impresso, a pesquisa aponta que as possibilidades de intervenção destes novos atores permanece fortemente orquestrada pelos próprios meios.

Palavras-chave: jornalismo e internet, cartas de leitores, cibercultura, cidadania digital.

Tabela comparativa entre as publicações observadas:

\begin{tabular}{|c|c|c|c|}
\hline & $\begin{array}{c}\text { CORREIO DO } \\
\text { LEITOR }\end{array}$ & COSMO ON LINE & $\begin{array}{c}\text { REVISTA } \\
\text { METRÓPOLE }\end{array}$ \\
\hline \multicolumn{4}{|l|}{ A-SEXO } \\
\hline MASCULINO & 237 & 84 & 28 \\
\hline FEMININO & 54 & 13 & 22 \\
\hline NĀO IDENTIFICA & 1 & & 1 \\
\hline TOTAIS & 292 & 97 & 51 \\
\hline \multicolumn{4}{|c|}{ B- PROFISSÃO (PRINCIPAIS) } \\
\hline Aposentados & 39 & \multirow{8}{*}{$\begin{array}{r}\text { Codinomes são todos } \\
\text { masculinos (Cidadão } \\
\text { Brasileiro, Justiceiro } \\
\text { Utópico, Pontepretano, } \\
\text { Paulo, Ramon...) }\end{array}$} & \\
\hline Professores & 28 & & 4 \\
\hline Empresários/Adm. & 27 & & \\
\hline Comunicador & 20 & & \\
\hline Comerciante & 20 & & 2 \\
\hline Engenheiro & 19 & & \\
\hline Servidor & 19 & & \\
\hline Advogado & 17 & & \\
\hline \multicolumn{4}{|c|}{ C- TEMAS MAIS COMENTADOS } \\
\hline Segurança pública & 13 & 53 & \multirow{12}{*}{$\begin{array}{r}\text { Conteúdos são todos } \\
\text { voltados a elogios (50) } \\
\text { ou crítica (1) } \\
\text { reportagens e textos } \\
\text { (crônicas) publicados }\end{array}$} \\
\hline Turismo & 13 & & \\
\hline Meio ambiente & 10 & & \\
\hline Asfalto & 10 & & \\
\hline Eleicôes & 30 & & \\
\hline Própria publicação & 30 & & \\
\hline Governo Lula & 26 & & \\
\hline Esportes & 16 & 31 & \\
\hline Interlocuções & 16 & & \\
\hline Polícia & 8 & & \\
\hline Entretenimento & & 12 & \\
\hline Política & & 1 & \\
\hline \multicolumn{4}{|c|}{ D-ORIGEM DAS MATERIAS } \\
\hline Ag. Anhanguera & & 49 & \\
\hline Ag. Estado & & 22 & \\
\hline "Casa" & Totalidade & 22 & Totalidade \\
\hline France Press & & 4 & \\
\hline \multicolumn{2}{|c|}{ E- NÚMERO DE MANIFESTAÇÕES } & \multicolumn{2}{|c|}{ Período de apuração dos conteúdos } \\
\hline Correio do Leitor & 292 & \multicolumn{2}{|c|}{ Agosto/Novembro de 2006 (4 semanas) } \\
\hline Cosmo On Line & 97 & \multicolumn{2}{|c|}{ Fevereiro/Março de 2007 (4 semanas) } \\
\hline Metrópole & 51 & \multicolumn{2}{|c|}{ Outubro/Janeiro de 2007 (4 semanas) } \\
\hline \multicolumn{4}{|c|}{ ENTREVISTAS E/OU QUESTIONÁRIOS RESPONDIDOS } \\
\hline Correio do Leitor & 5 & \multirow{3}{*}{\multicolumn{2}{|c|}{ Período: Entre março e julho de 2007}} \\
\hline Cosmo On Line & 4 & & \\
\hline Metrópole & 5 & & \\
\hline
\end{tabular}




\section{Introdução}

Estudar as possibilidades e efetivas intervenções que os leitores exercem sobre os atuais produtos midiáticos nos remete a uma questão precedente: Por que é importante estudar a mídia? Em parte, a resposta encontra-se no prefácio e no capítulo introdutório da obra em que Silverstone (2002, p. 9-32) tentou encontrar uma razão para indagações desta natureza:

Não podemos escapar à mídia. Ela está presente em todos os aspectos da nossa vida cotidiana. [...] Ela filtra e molda realidades cotidianas, por meio de suas representações singulares e múltiplas, fornecendo critérios, referências para a condução da vida diária, para a produção e a manutenção do senso comum.

O fato tem sido objeto da preocupação de inúmeros trabalhos desenvolvidos por pesquisadores da área, em especial os que se ocupam em propor uma teoria para a ação jornalística (WOLF, 1987; McCOMBS, 1992; KUNCZIK, 1997; CHAPARRO, 2001; SOUSA, 2002; entre outros). A preocupação se deve não apenas porque informação e o entretenimento representam as principais commodities no imenso mercado global que veio sendo delineado a partir do século XX, mas, principalmente, pelo papel que desempenha a mídia quando, a partir de suas produções, atribui significados e hierarquiza ocorrências sociais, propondo uma certa organização racional do mundo em que vivemos. A propósito do tema, Chaparro (1994 e 2001), vê no jornalismo a condição de cenário ou arena mesmo - em que os atores sociais colocam seus discursos visando conquistar adeptos às suas causas: sociais, políticas, culturais, comerciais. O autor, contudo, ressalva caber ao jornalista, por um princípio ético, a missão de garantir também o direito de discursividade aos despossuídos das condições discursivas midiáticas.

Nesta arena, o advento da Internet impactou profundamente as relações entre jornalistas e fontes noticiosas zanotti, 2002, trazendo ao universo da imprensa um contingente de novos atores sociais. $\mathrm{O}$ correio eletrônico foi o grande instrumento a mobilizar esses novos atores, já que tornou automática a relação entre eles e os jornalistas; entre eles e a imprensa; e entre eles próprios. Ao perceber essa intensi-dade no fluxo de informações, os portais noticiosos trataram de incorporar fóruns de discussões em suas páginas. Nas versões impressas, jornais e revistas também ampliaram os espaços historicamente destinados às cartas de leitores, tendo o jornal Correio Popular zanotti, 2007), orientado por uma agência catalã especializada em modernização gráfica, inovado as práticas tradi-cionais de publicação de cartas ao fazer chamadas de primeira página e incluir fotos dos rostos de seus leitores ao lado das cartas reprodu-zidas na publicação.

$\mathrm{O}$ incremento à publicação de cartas de leitores, bem como o estudo das manifestações postadas em portais noticiosos, tem a propriedade de oferecer elementos para estudos acerca dos perfis destes novos atores sociais, das temáticas que mais mobilizam a opinião pública, e da sincronia ou não entre eles e os veículos de comunicação nos quais se informam, além de poder revelar uma série de demandas não satisfeitas no processo de produção jornalística. Pesquisas neste sentido tendem a oferecer aos produtores de notícia elementos para uma maior 
satisfação de seus públicos, o que pode contribuir para aperfeiçoar o papel da mídia na construção da democracia, consolidar-se enquanto empresa (movimentando a economia e oferecendo empregos) e aperfeiçoar o papel social que desempenham no mundo contemporâneo.

A pesquisa aqui empreendida exigiu o cruzamento de pelo menos três temas que têm sido objeto de preocupação de pesquisadores: a Sociedade da Informação enquanto demandadora de conteúdos e tecnologias; a Internet enquanto instrumento de construção de um modelo particular de cultura e cidadania; e o jornalismo enquanto cenário de batalha discursiva entre sujeitos situados no campo da recepção.

Um dos autores a melhor se ocupar das temáticas afetas à Sociedade da Informação é o espanhol radicado nos EUA Manuel Castells (1999), que chama de "sociedade em rede" o patamar tecnológico no qual se assenta um modelo de sociedade global, altamente tecnizada, voltada à produção econômica e com uso intenso das novas tecnologias da informação e comunicação (TICs). Esse modelo de sociedade é também designado por "sociedade pósindustrial” (LYOTARD, 2002), "sociedade informática" (SCHAFF, 1995), "sociedade do conhecimento" (TOFLER, 1990) ou "sociedade tecnizada” (MACHADO, 1993).

Para os propósitos deste trabalho, escolhemos operar com Castells, para quem o termo rede designa muito mais que uma metáfora para a Internet. A expressão descreve "um conjunto de nós interconectados" (p. 498), que, por sua maleabilidade e flexibilidade, oferece uma ferramenta extremamente útil para lidar com a complexidade de configuração das sociedades contemporâneas sob o

Veículos em Perspectiva paradigma informacional, definindo ao mesmo tempo o conceito e as estruturas sociais empíricas. Referindo-se à Sociedade da Informação aos participantes do V Fórum Social Mundial realizado em Porto Alegre, Castells (2006, p. 225) a descreveu como

\section{[...] um período histórico caracterizado por uma revolução tecnológica centrada nas tecnologias digitais de informação e comunicação, concomitante, mas não causa- dora, com a emergência de uma estrutura social em rede, em todos os âmbitos da atividade humana, e com a interdepen- dência global desta atividade. É um processo de transformação multidimensional que é ao mesmo tempo includente $e$ excludente em função dos valores e interesses dominantes em cada processo, em cada país e em cada organização social.}

Temos também em Castells que o paradigma da sociedade informacional surge quando observa-se
“a transferência de uma tecnologia baseada principal- mente em insumos baratos de energia para uma outra que se baseia princi-palmente em insumos baratos de informação derivados do avanço da tecnologia em microeletrônica e telecomunicações" (grifo do autor).

Sendo assim, a sociedade (em rede) proposta na obra de Castells só é possível graças ao advento da rede mundial de computadores, a base tecnológica sobre a qual assenta-se um conjunto bastante rico de estudos de naturezas diversas. Ao nosso ver, a base tecnológica informacional indica uma "mudança de escala" que se operou na 
sociedade, como propunha McLuhan (1969) para mecanismos que, como a Internet, podem ser classificados como extensões humanas. Derrick de Kerckhove (1997), um dos herdeiros do pensamento deste pesquisador canadense notabilizado na década de 1960 , chega mesmo a propor uma fórmula para este novo estágio que se observa na história da humani-dade: Massa X Velocidade. A fórmula descreveria a condição de "prosumidores" de informação na qual todos fomos potencialmente transformados a partir da Internet, mecanismo que deu origem à Cibercultura, estágio de desenvolvimento tecno-social que encontrou em Lemos uma de suas mais precisas definições:

A Cibercultura forma-se precisamente da convergência entre o social e o tecnológico, sendo através da inclusão da 'socialidade' na técnica que ela adquire seus contornos mais nítidos. Não se trata obviamente de nenhum determinismo social ou tecnológico e sim de um processo simbiótico onde nenhuma das partes determina irreversivelmente a outra. A Cibercultura é a socialidade que se apropria da técnica.

Ao explorar o tema, Pierre Levy (1999) aponta que, antes de apresentar-se como uma técnica que leva à desumanização, a Cibercultura mostra-se como um "movimento" que responde ao desejo de autoformação $^{1}$ do indivíduo; à necessidade que cada um possui de apresentar-se como um ser próprio, diferenciado de uma massa homogênea. O autor aponta a existência de quatro espaços antropológicos que vieram sendo construídos sucessivamente ao longo da aventura humana: Terra, Território, Mercadoria e Saber. Este último coincide com o advento da Internet, meio que, se recorrermos à terminologia macluhiana, poderia ser enquadrado como "frio", já que oferece ao usuário possibilidades de inclusão, ao contrário da televisão que, por ser "quente" (saturar os sentidos), não deixa lacunas para intervenções do "leitor", havendo aî certa correspondência entre o pensamento do canadense e o conceito de obra aberta, de Umberto Eco, como bem observou Bulik (2002).

O movimento cibercultural, cuja base é a convergência entre tecnologia e sociedade, é, portanto, o cenário que estimula, via facilitação e disseminação de uso, o surgimento de novos atores sociais guindados a partir do território da recepção. Foi o que pudemos demonstrar quando apuramos o enorme salto no volume de cartas de leitores enviadas ao jornal "Correio Popular", de Campinas, após a adoção de correios eletrônicos por parte de seus repórteres e editores (ZANOTTI, 2002). Não fosse a facilidade com que passaram a se comunicar com jornais a partir da Internet, esses novos sujeitos não teriam participação tão ativa na produção da obra aberta em que se transformaram os produtos virtuais, em volume e velocidade de trocas (principalmente simbólicas) sem precedentes. Vale aqui resgatar o que diz Freitas (2000, p. 98) a respeito da importância das trocas:

Os antropólogos [...] deduziram que a troca traz algo além dos próprios objetos trocados: ela permite o estabelecimento de relações, não somente entre uns e outros, mas sobretudo entre cada um e alguma coisa maior do que eles mesmos, que é a própria sociedade.

Dadas às suas características, as 
colunas de leitores e os chamados fóruns de discussões que as versões virtuais das publicações impressas abrem em seus sítios noticiosos configuram-se, ao menos no campo midiático, comoum espaço privilegiado de trocas. Privilegiado porque, diferentemente de outras produções culturais (entre as quais o jornalismo se enquadra), a atividade jornalística é a única forma de comunicação social que, por sua pragmática, se propõe a oferecer um "atestado de veracidade" (CHAPARRO, 1994, p.121) às narrativas que constrói acerca do cotidiano.

A abordagem de Chaparro parece bastante oportuna aos propósitos deste trabalho, em função de dar um passo à frente em relação às teorias conspiratórias para a ação jornalística, sem que isso implique no abandono da tese do agendamento, como vista em McCombs (1992) ao defender que os meios não nos indicam apenas sobre o que pensar, mas também sobre como pensar acerca dos temas que são objeto de seus holofotes. Igualmente, no âmbito da produção propriamente dita de suas narrativas, o pensamento de Chaparro também não se opõe a uma dimensão "construcionista" da notícia (SOUSA, 2002), nem ao fato de que elas sejam resultado da interação de várias forças, situadas "ao nível das pessoas, do sistema social, da ideologia, da cultura, do meio físico e tecnológico, e da história" (p.17).

Em sua obra "Pragmática do Jornalismo", Chaparro propõe que o fator interesse pode ser considerado um atributo de definição do jornalismo. "Só é notícia o relato que projeta interesses, desperta interesses e responde a interesses", atesta o autor (p.119) recorrendo a Habermas (1987). A nosso ver, as cartas de leitores são hoje o espaço que, por excelência, reflete o interesse de boa parcela dos leitores

Veículos em Perspectiva advindos da Cibercultura. Erbolato (1981) sustentava que o volume de cartas de leitores às publicações impressas, numa época em que sequer existia o computador pessoal, podia ser tomado como evidência de fracasso ou sucesso de um determinado jornal. $\mathrm{O}$ tema também figura nos trabalhos de Assunção (2008), pesquisador da área de Letras, sob a questão dos gêneros textuais. Em pesquisa realizada em publicações impressas de várias modalidades (revistas, jornais, publicações segmentadas), o autor aponta:
A importância das cartas de leitores consiste no fato de elas acentuarem o caráter dialógico dos meios de informação, pois ao publicarem as cartas dos leitores, a princípio, indepen- dente do conteúdo veiculado o jornal não só dá voz aos seus leitores, permitindo que eles possam interagir não só com o jornal, mas também com outros leitores. Além disso, as cartas de leitores funcionam como um termômetro, pois além de demarcar os interesses dos leitores, demonstra o seu grau de receptividade da matéria e do trabalho desenvolvido.

Na confluência entre Cibercultura e publicação de cartas de leitores, temos um fenômeno que dá margens a várias análises acerca da sobrevivência ou não da imprensa diante das ameaças que enfrenta na concorrência com a Internet. $\mathrm{O}$ mais sintomático destes fenômenos é que, embora as publicações virtuais evitem limitar espaço para seus webleitores, é muito maior o número de cartas enviadas para as versões em papel quando comparado ao similar na rede, como demonstram os totais do item A da Tabela. Para Johnson (2001), devido à sua profusão, a ação jornalística tende a 
se diluir na net, o que estimularia a busca pelo espaço no papel. Arnt (2002) vai mais adiante:

[...] a Internet oferece a exposição de todos os acontecimentos ocorridos no mundo, em tempo real ou no tempo do leitor/navegador. Mas a leitura particularizada, o olhar através do filtro local - ao mesmo tempo plural e particular - continua sendo possivel somente através da imprensa. $O$ recorte de realidade oferecido pelos jornais diários; aleatórios, muitas vezes; unilaterais necessariamente; ideológico, quase sempre; é o que de melhor se inventou, até hoje, para transmitir à população a pluralidade de informações necessárias ao gerenciamento da vida cotidiana.

Embora respondam às preocupações relativas à sobrevivência da imprensa no cenário de competição com as publicações virtuais, as ponderações de Johnson e Arnt são insuficientes para dar conta do problema. Os autores não avaliam, em suas obras, o surgimento de um novo sujeito-leitor a partir da rede de computadores - um sujeito melhor instrumentalizado a intervir nas publicações convencionais ou virtuais, nas quais procurará, cada vez mais, participar da batalha discursiva orquestrada pelo jornalismo.

\section{Objetivos}

O trabalho empreendido teve por objetivo apurar as temáticas que mais mobilizam os cidadãos que descrevemos como webleitores próativos da cidade de Campinas aqueles que se informam e enviam comentários aos meios de comunicação escrita do município. Tais meios pertencem a um mesmo (e único) grupo editorial local, a Rede Anhanguera de Comunicação (RAC). São eles: o jornal diário "Correio Popular", para o qual escrevem cartas à coluna "Correio do Leitor"; o fórum "Comente esta notícia", do portal "Cosmo Online", no qual a empresa reproduz a quase totalidade dos textos da versão em papel; e a coluna "Cartas", da revista semanal "Metrópole", que circula encartada nas edições dominicais do "Correio Popular".

A partir deste levantamento de dados, pretendeu-se fazer inferências a respeito do perfil médio deste leitor, segundo as temáticas levantadas e traços de identidade (sexo, profissão) explicitados nas correspondências, além de dados obtidos em entrevistas e/ou questionários respondidos por eles. Por fim, pretendeu-se ainda avaliar os limites desta pró-atividade a partir das ferramentas disponibilizadas por tais publicações.

\section{Método}

É preciso ponderar que nenhuma metodologia de trabalho daria garantias totais acerca dos dados que aqui se pretendeu buscar. $\mathrm{O}$ que procuramos foram pistas que ajudassem a reduzir incertezas na compreensão de um fenômeno que, até por estar inserido no campo das ciências sociais, está afeto a um elevado grau de complexidade. Ciente destas limitações, adotamos uma metodologia híbrida de trabalho, como tradicionalmente têm sido usadas nos estudos em comunicação (MACHADO, 2007), em que combinamos a análise conteudística (quantitativa) a técnicas de entrevista e observação direta. Por Análise de Conteúdo entende-se "uma técnica 
de investigação que, através de uma descrição objetiva, sistemática e quantitativa do conteúdo manifesto das comunicações, tem por finalidade a interpretação destas mesmas comunicações" (BARDIN, 1977). Através deste tipo de análise, pretendemos conhecer quais motivações e temas presentes no universo midiático ocupam as preocupações de parte da população de internautas da cidade de Campinas, já que, por analogia, temse em Freitas (2000, p. 40) que:

[...] o médico faz suas deduções sobre a saúde de seu paciente graças aos seus sintomas, o meteorologista faz a previsão do tempo inferindo sobre estados ou posições da natureza. Ocorre o mesmo dentro da Análise de Conteúdo, pela dedução através da leitura e compreensão das mensagens.

O levantamento de dados para a análise das cartas de leitores deu-se ao longo de quatro semanas entre os meses de Agosto de 2006 e março de 2007, procurando-se evitar a concentração de temas em torno de um único assunto, como as eleições presidenciais, por exemplo, que ocorreram no período. As 440 cartas catalogadas foram reduzidas a unidades de informação que apontassem quais temáticas teriam motivado os comentários dos leitores. Em seguida, os nomes que mais se repetiam eram anotados à parte para a solicitação de entrevistas.

Os entrevistados, que compreenderam o aspecto qualitativo do trabalho, foram escolhidos de forma a representar, por gênero e profissão (sempre que possível), uma amostra equilibrada do universo pesquisado, já que, nos fóruns citados, os leitores são obrigados a se identificar ao final de suas cartas. Eles foram localizados a partir de seus endereços eletrônicos (publicados), lista telefônica e/ou intermediação através do próprio jornal. Ao todo, 14 autores atenderam ao convite, sendo que a maioria preferiu responder a um questionário a submeter-se a uma entrevista pessoal. A entrevista focalizada (quando possível) foi adotada como método de investigação na tentativa de se obter informações de caráter sócio-biográfico e melhor compreender esses novos sujeitos que, a partir da Internet, propõem seus discursos ao cenário midiático.

Resultados

O jornal: Fundado em 4 de setembro de 1927, atualmente com tiragem diária de 50 mil exemplares na cidade de Campinas (SP), o "Correio Popular" disponibiliza peló menos $70 \%$ de seu espaço editorial da página 2 do primeiro caderno à publicação das cartas de seus leitores, com média diária de 11 correspondências. Ao que se sabe, o jornal é o único no Brasil a publicar fotografias do rosto de seus missivistas, bem como chamadas na primeira página para os conteúdos de tais correspondências, estratégia adotada já em 2006 (ZANOTTI, 2007).

Ao todo, o jornal publicou 292 cartas no período, das quais $81 \%$ enviadas por remetentes do sexo masculino e outros $18,5 \%$ pelo sexo feminino, havendo apenas uma manifestação assinada por instituição. Em relação à cidade a partir da qual o remetente enviou seu email, apurou-se que $96 \%$ deles o fizeram do próprio município de Campinas, sendo os demais de Paulínia, São Paulo, Rio de Janeiro e São Bernardo do Campo, entre algumas da Região Metropolitana de Campinas (RMC).

Em relação à profissão, o maior 
número de missivistas é constituído por aposentados, com $13,3 \%$ do total de correspondências, cabendo o segundo lugar aos professores $(9,5 \%)$, seguidos por administradores ou empresários $(9,2 \%)$, comunicadores $(7 \%)$ e vendedores $(7 \%)$, entre outras menos citadas. $\mathrm{O}$ maior número de manifestação referiu-se à gestão político-administrativa do município (23\%), havendo também uma prevalência da gestão do país (8\%) e comentários a reportagens publicadas pelo jornal (10\%). As interlocuções -o debate público entre leitores- responderam por apenas $5 \%$ do total.

O portal: Também pertencente à Rede Anhanguera de Comunicação (RAC), o portal reproduz textos de seus periódicos (jornal "Correio Popular", jornal "Diário do Povo", revista "Metrópole", "Gazeta do Cambuî" e "Gazeta de Ribeirão"), além de manter uma equipe própria para produzir conteúdos específicos. No portal, o levantamento do corpus deu-se entre os meses de fevereiro e março de 2007, sendo duas semanas de cada mês. Por se tratar de publicação virtual, realizamos o levantamento de dados sempre às $20 \mathrm{~h}$ de cada dia, horário em que o site já produzira grande parte das notícias. Devido ao grande volume de notícias disponibilizadas, deu-se prioridade apenas para as reportagens que eram manchetes e que estavam dispostas na página inicial do site. A pesquisa envolveu uma média de 25 matérias diárias, que versaram principalmente sobre Política, Economia, Saúde, Esporte, Educação, Cidadania, etc., em Campinas e região.

O levantamento de dados revelou que, dos 268 relatos jornalísticos publicados, 226 não possuíam qualquer comentário, contra 42 que estavam acompanhados de comentários de webleitores, muitos dos quais se repetiam. Nas 42 matérias comentadas, encontramos um total 97 comentários postados, pouco mais de dois, portanto, por relato noticioso. Uma primeira observação permitiu perceber que a maioria das manifestações fora enviada por internautas que preferiram omitir sua identidade, usando pseudônimos para tanto ( $34 \%$ ), contra $28,9 \%$ que revelam apenas seus pré-nomes e $19,6 \%$ que revelaram seus nomes completos; do conjunto, $17,5 \%$ não assinaram seus comentários.

Ao postar comentário no portal, é possibilitado ao webleitor que divulgue sua conta de correio eletrônico, opção adotada por apenas $23,7 \%$ dos missivistas, contra $76,3 \%$ que preferiram não o fazer. A leitura dos nomes permitiu também supor o sexo do remetente: $75,2 \%$ de homens, contra $5,1 \%$ de mulheres, e $19,6 \%$ cujos pseudônimos não ofereceram indicações de gênero. A grande maioria dos comentários referia-se aos textos produzidos pela Agência Anhanguera, da própria $\mathrm{RAC}$, indicando tratarem-se de temas locais e regionais, contra $16,7 \%$ de temas produzidos pela Agência Estado (nacional) e apenas $2,4 \%$ pela internacional France Press.

Em relação à temática, a maioria dos comentários concentrou-se na área da violência, com $63,7 \%$ das manifestações, ficando um distante segundo lugar para a temática relativa ao esporte, com $10,3 \%$.

Diferentemente dos leitores da coluna "Correio do Leitor", o internauta que envia comentários ao fórum "Comente esta notícia" extravasa com mais impulsividade suas opiniões. Outra particularidade deve-se ao fato de que os internautas, até por terem espaço livre para suas manifestações, o fazem com maior incidência. Eles não são tão numerosos nem tão diversi- 
ficados como ocorre na coluna do jornal em papel.

A revista: Terceiro espaço de análise, a revista Metrópole circula dominicalmente, há 7 anos, encartada nas edições do jornal "Correio Popular”. Com média de 52 páginas, a publicação aborda temas que fogem da cobertura jornalística que caracteriza o dia-a-dia da imprensa - o chamado hard-news, dedicandose a uma temática voltada a informações de comportamento, moda, culinária, modo de vida, saúde, sociedade e roteiro gastronômico. Com textos que evitam asperezas ${ }^{2}$, a publicação ainda acolhe crônicas e críticas culturais.

Para a publicação das cartas de leitores, a revista reserva apenas uma coluna da página 4 , sob o título de "Cartas", abaixo do qual geralmente figuram entre quatro $\mathrm{e}$ cinco manifestações. A exemplo da coluna "Correio do Leitor", a publicação também limita o tamanho de texto que acolhe no formato de cartas: 15 linhas, com identificação do remetente, advertindo que "A redação se dá o direito de resumir as cartas de acordo com o espaço". Observou-se uma grande prevalência da publicação de cartas elogiando os conteúdos da revista ou seus jornalistas, com $48 \%$ do total apurado, para logo em seguida emendar uma sugestão, complemento e/ou elogios a personagens abordados nas reportagens.

\section{Discussão}

À luz da revisão bibliográfica e das evidências recolhidas na pesquisa de campo, os dados indicam que as cartas dos leitores pró-ativos das publicações analisadas referem-se basicamente aos temas propostos pelas publicações nas coberturas que realizam. Primeiramente, por que a própria política editorial dos

Veículos em Perspectiva periódicos induz seu leitor, através do conjunto de cartas publicadas, a referir-se exclusivamente aos conteúdos noticiados; e em segundo lugar por que não há, nos espaços destinados aos leitores, principalmente em se tratando do meio virtual, a possibilidade de abrir novas temáticas. Assim sendo, a próatividade do leitor em questão é relativizada em função de projetos editoriais que, no jornalismo contemporâneo, desestimulam a introdução de novas temáticas no universo de coberturas noticiosas.

Como bem apontou McCombs (1992), a mídia tem o poder de definir os temas sobre os quais a sociedade deve pensar; e acrescente-se: dá-lhe uma falsa idéia, via carta de leitores, de que ele tem participação efetiva neste universo. O leitor, mesmo com estas limitações, não se furta ao direito de colocar seus discursos nesses espaços de visibilidade. Temse também que a adoção da Internet como ferramenta de participação dos leitores nos fóruns de discussão serviu para aumentar volume e velocidade no trânsito de comunicação entre leitor e jornalismo, mas não para alterar a chamada agenda midiática.

O item B da TABELA aponta que as cartas enviadas aos jornais são majoritariamente produzidas pelos estratos melhor situados na pirâmide social brasileira, o que implica no fato de que a parcela excluída do desenvolvimento também se faz excluída dos meios de comunicação enquanto membros pró-ativos. Bem por isso, as temáticas predominantes são aquelas que interessam mais de perto àquele contingente, como política e segurança pública, da qual sentemse vítimas preferenciais. A mesma tabela (item D) aponta que há um maior interesse pelos temas mais imediatos, que interferem no

${ }^{2}$ Referimo-nos ao fato de a publicação não tocar em temas conflituosos, que desagradem a qualquer um de seus leitores potenciais. 
cotidiano do leitor enquanto habitante/morador/contribuinte de uma determinada região geográfica, haja vista a procedência das notícias publicadas (Agência Anhanguera).

No item $C$ da TABELA, tem-se que a totalidade das cartas publicadas na revista Metrópole tem característica endógena, referindose exclusivamente à qualidade dos textos publicados, e não necessariamente à temática levantada. A falta de aspereza (BOURDIEU, 1997) nas reportagens pode ser responsabilizada por esta propriedade. O mesmo item de tabela indica que, no mundo virtual, as manifestações estão majoritariamente concentradas em temas relativos à segurança pública (ou à sua carência). Os itens $B$ e E revelam que, no mundo virtual, os remetentes preferem usar codinomes em suas assinaturas, omitindo, na maioria dos casos, seus endereços eletrônicos; eles também são em número bem menor que os remetentes para o universo do papel. No item $\mathrm{A}$, temos que o missivista do jornal impresso é predominantemente do sexo masculino, característica que se acentua no universo virtual, enquanto existe equilíbrio de gênero na revista semanal.

Os temas políticos ocupam densamente a preocupação dos missivistas do jornal "Correio Popular" no que se refere à gestão municipal $(23 \%)$ e ao cenário nacional, que, se agrupadas as temáticas "Lula" e "Eleições", atinge-se o patamar de $18 \%$ das manifestações. No plano local, segurança pública, turismo e meio ambiente ocupam espaço privilegiado no volume de cartas, o que comprova uma crescente demanda pelas coberturas relativas à ecologia, muito em função da visibilidade que o tema ganhou a partir da divulgação da tese do aquecimento global.

A apuração indica haver prevalência do tema segurança pública (violência) também nas motivações do webleitor. Em função da liberdade que o anonimato lhe dá, já que prefere usar codinome (o que é impossibilitado pela publicação impressa), observa-se um número maior de ataques às instituições governamentais ou seus titulares, resvalando inclusive para o território das chacotas. Os codinomes dão uma clara idéia da condição em que se colocam tais missivistas: " $\mathrm{O}$ Justiceiro" e "Justiceiro Utópico", sendo os que mais comentários enviam.

Na revista "Metrópole", percebeu-se que o remetente ocupa-se prioritariamente em tecer elogios à publicação, aos seus textos ou aos seus profissionais. Equilibrados entre os sexos masculino e feminino, os missivistas aparentemente concentram-se nos estratos sociais mais elevados. Tanto quanto na coluna "Correio do Leitor", há grande incidência de professores, bem como de aposentados, com a ressalva de que no meio impresso ainda figuram os comunicadores, a maioria deles engajada em organizações não governamentais e/ou assessoria institucional de imprensa.

Além de ser predominantemente do sexo masculino, o leitor pró-ativo do Município de Campinas possui instrução superior e renda mensal que o coloca nos estratos mais elevados da pirâmide social, conforme demonstram as entrevistas e/ou questionários recolhidos junto a eles. Os mais jovens manifestam-se nos espaços virtuais, enquanto os de faixa etária mais elevada preferem remeter seus comentários ao meio impresso, o mais disputado. Embora a maioria não tenha filiação partidária nem vote doutrinariamente em partido político, os que assinam ficha partidária o fazem nos partidos que militam no centro-esquerda, como 
PT e PSDB. Ao se definirem ideologicamente, colocam-se no campo do centro-esquerda, alguns arriscando para si definições como "socialista", "esquerda democrática" ou "comunista". Apenas um se coloca no campo da "direita", dizendo-se "crítico".

Dos 14 ouvidos, 5 dizem militar em organizações não governamentais, o que pressupõe que o engajamento comunitário associa-se a uma necessidade de partilhar o pensamento em público. Majoritariamente, são leitores diários de jornais impressos, com prevalência para o "Correio Popular", assinado por muitos, e "Folha de S.Paulo" e "Estado de S.Paulo", lidos nos respectivos ambientes de trabalho. "Veja" é a revista lida pela maioria dos que declaram ler periódicos não diários, categoria em que se enquadram 11 dos leitores pró-ativos, havendo também o que lê a revista "Caros Amigos". Os webleitores, localizados na faixa etária mais jovem, pertencem ao que se poderia denominar de "geração Internet", tendo entrado em contato com a rede de computadores na adolescência; os de faixa mais elevada aproximaram-se do computador por questões profissionais, tendo incorporado a Internet no seu dia-adia desde então.

Ao enviar seus comentários, esses leitores dizem experimentar a sensação do "dever cumprido", no sentido terem agido para "mudar alguma coisa". Esse sentimento de satisfação os leva, nos dias (ou horas) seguintes a conferir se houve, da parte de outros leitores (navegadores), alguma mensagem de apoio ou contestação ao que tenham escrito. Os autores dos textos do meio impresso chegam a receber pedidos para escreverem sobre determinados assuntos; já os do meio virtual não observam repercussão alguma dos

Veículos em Perspectiva comentários que postam.

Parte desses leitores mantém páginas pessoais na Internet e/ou participam de comunidades virtuais, em especial aquelas formadas em função de unidades escolares, mesmo que de anos anteriores. Os não nascidos no Município de Campinas não se interessam em navegar em páginas de suas cidades de origem, mas consideram um exercício de cidadania manifestarem-se nos fóruns de leitores. Seu conceito de cidadania está ligado à possibilidade de manifestação do pensamento, o exercício de deveres e direitos, a responsabilidade para com o coletivo e o exercício da ética. Embora alguns tenham o hábito de enviar emails a autoridades e prestadores de serviços públicos, todos acreditam em uma maior efetividade nas reclamações publicadas em jornais, em função da repercussão midiática.

\section{Conclusão}

A participação de fóruns de leitores, em especial das colunas que os jornais impressos reservam para este fim, é considerada um mecanismo mais efetivo para pressionar o poder público a atender reivindicações do que qualquer manifestação feita diretamente aos responsáveis por tais atendimentos. Bem por isso, os chamados leitores próativos, aqueles que interagem enviando manifestações aos veículos de comunicação que assinam ou lêem, adotam esse mecanismo para encaminhar críticas, sugestões e reivindicações ao poder público, em especial através dos meios impressos, nos quais observam existir maior repercussão de suas vozes na comparação que fazem com o meio virtual.

Os espaços disponíveis para tal finalidade, contudo, são dotados de

Comunicação \& Informação v. 11 , n. 1: p. $67-79$ - jan./jun. 2008 
determinadas regras de conduta que, somadas à sua finalidade implícita, limitam o leque da pró-atividade. $\mathrm{O}$ leitor é conduzido, na maioria das vezes, a manifestar-se sobre os temas que compõem a agenda midiática, evidentemente não definida por ele - fato sobre o qual o leitor não elabora reflexões. O engajamento em organizações sociais, bem como filiação ou preferência pelos partidos de centroesquerda, é traço comum ao perfil desses missivistas, indicando uma estreita relação entre os dois fenômenos.

\section{Abstract}

This paper presents the results of a research involving 440 letters of readers, sent via Internet, to readers' columns of three journalistic publications of the city of Campinas (SP): a daily newspaper, a weekly magazine and a news portal, all of them belonging to the same editorial group. As for discoursive scenarios, these spaces reflect profiles, worries and interests of the new mediatic subjects made possible by the most important tool of the new media - the electronic mail. Besides registering clear preference for the use of the printed means, the research points out that to the possibilities of intervention of these new actors remain strongly orchestrated by these same means.

Key Words: journalism and Internet, letters of readers, cyberculture, digital citizenship.

\section{Referências}

ARNT, Héris. Do jornal impresso ao digital: novas funções comunicacionais. Trabalho apresentado no NPO2 - Núcleo de Pesquisa Jornalismo, XXV Congresso Brasileiro de Ciências da Comunicação, Salvador/BA, 04 e 05 setembro de 2002.

ASSUNÇÃO, Luiz Antonio. Cartas de Leitores : Reescrita e Condições de Produção de um gênero midiático.
Acesso em http://www3.unisul.br/ paginas/ensino/pos/ linguagem/ cd/ Port/22.pdf.

BARDIN, Laurence. Análise de Conteúdo. Tradução Luís Antero Reto e Augusto Pinheiro. Lisboa (Portugal): Edições 70, 1977.

BOURDIEU, Pierre - Sobre a televisão. Rio de Janeiro: Jorge Zahar, 1997.

BULIK, Linda. Na órbita da galáxia de Gutenberg. Trabalho apresentado no NP01 - Núcleo de Pesquisa Teorias da Comunicação, XXV Congresso Anual em Ciência da Comunicação, Salvador/ BA, 04 e 05 de setembro de 2002.

CASTELLS, Manuel. A sociedade em rede. São Paulo: Paz e Terra, 1999.

. Manuel. Inovação, liberdade e poder na Era da Informação. In: MORAES, Dênis de (org.). Sociedade midiatizada. Rio de Janeiro: Mauad, 2006.

CHAPARRO, Manuel Carlos. Pragmática do Jornalismo: buscas práticas para uma teoria da ação jornalística. São Paulo: Summus, 1994.

Manuel Carlos. Linguagem dos Conflitos. Coimbra: Minerva Coimbra, 2001.

ERBOLATO, Mário L. Jornalismo Especializado: Emissão de textos no jornalismo impresso. São Paulo: Atlas, 1981.

FREITAS, Henrique Mello Rodrigues de. Análise léxica e análise de conteúdo: técnicas complementares, sequenciais e recorrentes para exploração de dados qualitativos. Porto Alegre: Sphinx: Editora Sagra Luzzatto, 2000.

HABERMAS, Jürgen. Conhecimento e Interesse. Rio de Janeiro: Editora Guanabara, 1987, pp. 211-233. 
JOHNSON, Steven. Cultura da interface: como o computador transforma nossa maneira de criar e comunicar. Trad. Maria Luiza X. de A. Borges. Rio de Janeiro, Jorge Zahar Editor, 2001.

KERCKHOVE, Derrick de. A pele da cultura: uma investigação sobre a nova realidade eletrônica. Lisboa: Relógio D’Água Editores, 1997.

KUNCZIK, Michael. Conceitos de jornalismo: Norte e Sul: Manual de Comunicação. Tradução Rafael Varela Jr. São Paulo: Universidade de São Paulo, 1997.

LEMOS, André. Ciber-socialidade. Tecnologia e vida social na cultura contemporânea. Disponível em: http:// www.facom.ufba.br/pesq/cyber/lemos/

LEVY, Pierre. Cibercultura. Trad. Carlos Irineu da Costa. São Paulo: Editora 34, Coleção Trans, 1999.

LYOTARD, Jean-François. A condição pós-moderna. Tradução Ricardo Corrêa Barbosa, $7^{\text {a }}$. Ed., Rio de Janeiro: José Olympio, 2002.

MACHADO, E. Metodologias aplicadas ao estudo do ensino de jornalismo digital. Trabalho apresentado no $5^{\circ}$. Encontro Nacional de Pesquisadores em Jorna-lismo. Universidade Federal de Sergipe, 15 a 17 de nov. 2007.

MACHADO, Lucília. Sociedade industrial $X$ sociedade tecnizada. Universidade e Sociedade, ano III, n. 5, julho 1993, p. 32-37.

McCOMBS, Maxwell E. Explorers and Surveyors: Expanding Strategies for Agenda-Setting Research. Journalism Quarterly, Vol. 69, 1992.
McLUHAN, Marshall. Os meios de comunicação como extensões do homem (Understanding media: The Extensions of Man). Tradução Décio Pignatari. São Paulo: Cultrix, 1969.

SCHAFF, Adam. A sociedade informática. São Paulo: Brasiliense, 1995.

SILVERSTONE, Roger. Por que estudar a mídia? Tradução Milton Camargo Mota. São Paulo: Loyola, 2002.

SOUSA, Jorge Pedro. Teorias da notícia e do jornalismo. Chapecó: Argos 2002.

THOMPSON, John B. A mídia e a modernidade: uma teoria social da mídia. Petrópolis (RJ): Vozes, 1998.

TOFFLER, Alvin. Powershift. Rio de Janeiro: Record, 1990.

WOLF, Mauro. Teorias da Comunicação. Lisboa: Presença, 2003.

ZANOTTI, Carlos Alberto. Gutenberg cai na rede: um estudo das transformações que a rede mundial de computadores vem impondo aos processos de produção da imprensa diária. Tese de doutorado defendida programa de pós-graduação em Ciências da Comunicação da Escola de Comunicações e Artes da Universidade de São Paulo (ECA-USP) em 9 de setembro de 2002.

. Leitor na primeira página: um estímulo à interatividade em diário da cidade de Campinas. Actas das II Jornadas Internacionais de Jornalismo. Por que estudar Jornalismo? Porto: Universidade Fernando Pessoa, 2007 (pp. 397-411).

Data do recebimento: 26/05/2008

Data do aceite: 05/06/2008

Comunicação \& Informação v. 11 , n. 1 : p. $67-79$ - jan./jun. 2008 